\title{
Reconstruction of the cervical skeleton posture of Brachiosaurus brancai Janensch, 1914 by an analysis of the intervertebral stress along the neck and a comparison with the results of different approaches
}

\author{
Andreas Christian* \& Gordon Dzemski** \\ Universität Flensburg, Institut für Biologie und Sachunterricht und ihre Didaktik, Auf dem Campus 1, 24943 Flensburg, Germany
}

Received 15 July 2006, accepted 12 August 2006

Published online 30 January 2007

With 8 figures and 2 tables

Key words: Brachiosaurus, sauropod, neck, feeding, biomechanics, functional morphology, ecology.

\begin{abstract}
The neck posture of Brachiosaurus brancai Janensch, 1914 is reanalysed by employing the Preuschoft method to deduce the pattern of stress in the joints between the vertebral centra along the neck. The cogency of different methods for reconstructing the posture of a long neck, especially the Preuschoft method and approaches that are based on optimal articulation of the neck vertebrae, is discussed critically. The results corroborate the reliability of the Preuschoft method whereas the analyses of recent vertebrates with long necks show that approaches based on optimal articulation of the neck vertebrae are less suited for reconstructing habitual postures of long necks during rest. Such models are better suited for reconstructing the neck posture that was employed during locomotion. With the evidence obtained by different methods a conclusive picture of the neck posture and the feeding strategy of Brachiosaurus brancai can be drawn. The neck appears to have been slightly S-shaped with a ventrally flexed cranial section, an approximately straight middle section, and a dorsally flexed proximal part. In the habitual posture during standing, the angle between the middle section of the neck and the horizontal plane was about $60^{\circ}$ or $70^{\circ}$. During locomotion the whole neck probably was kept in an lower position with the inclination reduced by approximately $20^{\circ}$ compared with the position at rest. During feeding movements of the head relative to the neck and movements in the cranial neck section were performed without much altering the height of the centre of gravity of the neck. With slow dorsoventral movements of the whole neck pronounced changes in the feeding height were possible. Sideways movements of the whole neck were performed by lateral flexion at the base of the neck. According to these findings, the long neck of Brachiosaurus brancai was a means for browsing in great heights as well as a means for increasing the feeding volume without moving the body.
\end{abstract}

Schlüsselwörter: Brachiosaurus, Sauropoden, Hals, Nahrungsaufnahme, Biomechanik, funktionelle Morphologie, Ökologie.

\section{Zusammenfassung}

Die Halsstellung von Brachiosaurus brancai Janensch, 1914 wird mit Hilfe der Preuschoft-Methode untersucht, die auf der Ermittlung der Spannungen in den Gelenken zwischen den Wirbelkörpern entlang des Halses beruht. Verschiedene Rekonstruktionsmethoden langer Hälse werden hinsichtlich ihrer Aussagekraft kritisch betrachtet, insbesondere die PreuschoftMethode sowie Ansätze, die auf einer optimalen Gelenkung zwischen den Wirbeln beruhen. Die Ergebnisse untermauern die Zuverlässigkeit der Preuschoft-Methode, während Analysen an langen Hälsen rezenter Wirbeltiere zeigen, dass Modelle mit optimaler Gelenkung sich weniger für die Rekonstruktion der habituellen Halsstellung während der Ruhe eignen. Stattdessen scheinen solche Modelle eher den Halsstellungen bei der Fortbewegung nahe zu kommen. Unter Einbeziehung verschiedener Methoden wird ein schlüssiges Bild der Halsstellung und der Ernährungsstrategie von Brachiosaurus brancai gezeichnet. Der Hals wurde offenbar in einer leichten S-Form gehalten, mit einem ventralflektierten vorderen Halsabschnitt, einer etwa gerade gehaltenen Halsmitte und einer dorsalflektierten Halsbasis. In der habituellen Stellung des stehenden Tieres bildete die Halsmitte einen Winkel von etwa $60^{\circ}$ oder $70^{\circ}$ mit der Horizontalebene. Bei der Fortbewegung wurde der Hals vermutlich um rund $20^{\circ}$ niedriger gehalten als in der Ruheposition. Während der Nahrungsaufnahme konnte der Kopf durch Bewegungen allein des vorderen Halsabschnittes positioniert werden, ohne dass dabei der Schwerpunkt des Halses wesentliche Höhenänderungen erfahren hätte. Langsame dorsoventrale Bewegungen des gesamten Halses ermöglichten auch erhebliche Ände-

\footnotetext{
* Corresponding author: e-mail: gachrist@aol.com, christian@uni-flensburg.de

**E-mail: dzemski@uni-flensburg.de
} 
rungen der Kopfhöhe. Seitliche Bewegungen des gesamten Halses konnten an der Halsbasis erzeugt werden. Gemäß dieser Ergebnisse war der lange Hals von Brachiosaurus brancai sowohl ein Mittel zum Erreichen von Nahrungsquellen in großer Höhe als auch zur Vergrößerung des Volumens, das bei ruhendem Körper mit dem Kopf erreicht werden konnte.

\section{Introduction}

A long neck is a characteristic feature of all sauropod dinosaurs (e.g., McIntosh 1990). In Brachiosaurus brancai Janensch, 1914, the neck comprises about $2 / 3$ of the presacral vertebral column (Janensch 1950a, 1950b). The feeding strategy of sauropods depends on the posture and mobility of the neck. The neck posture is the subject of much controversy. The neck is either interpreted as a means for high browsing (e.g., Bakker 1987; Paul 1987, 1988) or for increasing the horizontal feeding range (e.g., Martin 1987). Different sauropod species possibly employed different feeding strategies (e.g., Dodson 1990). This assumption appears reasonable from an ecological point of view and also fits to the diversity of jaw and tooth morphology observed among sauropods (e.g., Upchurch \& Barrett 2000; Sereno \& Wilson 2005). For Brachiosaurus, the suggested neck posture differs between horizontal (Frey \& Martin 1997; Berman \& Rothschild 2005; Stevens \& Parrish 2005a, 2005b) and forwardly inclined or nearly vertical (Janensch 1950b; Bakker 1987; Paul 1987, 1988; Christian \& Heinrich 1998; Christian 2002a, 2002b, 2004).

The term "feeding strategy" is used here for the way the food is chosen from different heights and distances, e.g. by keeping the neck in a high or in a low position or by frequent changes of the height of the head. Closely related are the questions which food was chosen (e.g., Farlow 1987) and how was the food separated from the source, e.g. from a tree (e.g., Upchurch \& Barrett 2000; Sereno \& Wilson 2005). It can be expected that the mean feeding height and therefore the preferred neck posture of a sauropod correspond to the distribution of the food that was chosen (see e.g. Upchurch \& Barrett 2000).

Differences in the reconstructed neck posture for Brachiosaurus brancai and other sauropods depend on the methods that are used for the reconstructions. The models proposed by Stevens and Parrish $(1999,2005 a, 2005 b)$ are based on proper articulation between the neck vertebrae, especially in the zygapophyses. Such "zygapophyseal alignment" or "best-fit" postures tend to be comparatively low. Gunga \& Kirsch (2001) conclude from studies of the inner ear, that the neck posture of Brachiosaurus varied from a vertical to a more horizontal posture during feeding. According to Berman \& Rothschild (2005) the internal structure of the ver- tebral centra in the neck of Brachiosaurus and other sauropods with very long necks indicate a horizontal position of the neck. The neck posture is also related to the overall construction of a sauropod (e.g., Alexander 1989; Christian 2002a, 2002b). The overall body design of Brachiosaurus indicates an elevated position of the neck (Christian 2002a, 2002b; see also discussion).

In this study the neck posture of Brachiosaurus brancai Janensch, 1914 is reanalysed by applying the Preuschoft method that was already employed by Christian \& Heinrich (1998). The reconstruction presented here, however, is improved especially by refined models of the mass distribution along the head and neck. According to more recent mass estimates (e.g., Henderson 1999, 2004; Seebacher 2001; Wedel 2005) the body and neck mass of sauropods probably were much below the estimates presented by Gunga et al. (1995) and Gunga et al. (1999) that were used in the previous reconstruction (Christian \& Heinrich 1998). The estimates of lever arms of epaxial muscles and ligaments and of cross-sectional areas of the intervertebral joints in the neck of Brachiosaurus brancai are also improved by only using the original material available at the Museum für Naturkunde der Humboldt-Universität zu Berlin instead of the reconstructed skeleton of Brachiosaurus brancai that is mounted for display. The new results obtained here are compared with the results by Christian \& Heinrich (1998) in order to test the robustness of the Preuschoft method. The "zygapophyseal alignment" approach is tested by analysing the neck postures of three recent vertebrates with long necks: giraffes, camels and ostriches.

The two major goals of this study are, first, to test the reliability of different methods for reconstructing the neck postures of sauropods, and second, to find a neck posture for Brachiosaurus brancai that is consistent with the results of different approaches.

\section{Material and Methods}

Skeletal remains of Brachiosaurus brancai used for the study. This study is based on the skeletal remains of Brachiosaurus brancai Janensch, 1914, that were excavated by the German Tendaguru Expedition between 1909 and 1912 (Janensch 1914a, 1914b). The exhibited skeleton at the Museum für Naturkunde der Humboldt-Universität zu Berlin is a composite of original bones, copies of bones, and plaster 
reconstructions of the missing parts (Janensch 1938, 1950b; for a detailed description of the palaeontological setting see also Christian \& Heinrich 1998). The major part of the composite skeleton belongs to one single individual of Brachiosaurus brancai, specimen S II. A second slightly smaller specimen (S I) yielded additional material not represented in specimen S II, e.g. the braincase and the axis. Some missing elements of skeleton S II either have been substituted by bones of other specimens of the same species and size or by plaster reconstructions. Other missing items have been replaced by bones or copies of bones from different-sized specimens, also of the same species. Of the 13 cervicals described by Janensch (1950a), the centra of the cervicals 3 to 13 and the spinal processes of the cervicals $3,4,5$, and 8 are well preserved in specimen S II. The cervicals 2 (axis) to 7 are well preserved in specimen S I. The centra of the first two dorsal vertebrae are preserved in connection with the centra of the proximal cervicals (S II). The analysis is focused on the section of the neck from the head to the caudal end of the eighth vertebra which comprises slightly more than half of the neck length. The mechanical calculations described below are based on the dimensions of the vertebrae of specimen S II. Specimen S I is used for reconstructing dimensions that cannot be determined directly for specimen S II, especially the dimensions of the atlas and the heights of the neural spines in the vertebrae 6 and 7 .

The dimensions of the head were estimated from the well preserved head skeleton of specimen $\mathrm{t} 1$. Isolated remains of the head skeleton of specimen S II (Heinrich, pers. com.) indicate that the length dimensions of the head were approximately one sixth longer in specimen S II than in specimen $\mathrm{t} 1$.

The Preuschoft-Method. The neck posture is reconstructed by applying the method developed by Preuschoft (1976) to deduce the patterns of stress in the intervertebral discs along the neck (for a detailed description see Christian \& Heinrich 1998; or Christian 2002a). Assuming similar safety factors along the neck and a predominance of static or quasistatic forces, neck postures in which the stress is not more or less constant along the neck are rejected, whereas habitual postures are characterised by approximately constant stress values in the intervertebral joints.

As long as the neck is not orientated backwards, bending moments along the neck must be counteracted at the joints between the vertebral centra by tension in epaxial muscles, tendons, or ligaments that are located dorsal to the centra (Preuschoft 1976; Alexander 1985, 1989; Christian \& Preuschoft 1996; Christian \& Heinrich 1998; Christian 2002a). A muscle, tendon, or ligament force $F_{m}$ acting in a sagittal plane dorsal to the transverse axis of an intervertebral joint produces a torque $\mathrm{F}_{\mathrm{m}} \cdot \mathrm{h}$ about that joint, where $\mathrm{h}$ is the lever arm of the force $F_{m}$ (Fig. 1). The lever arm is the distance between the line of action of the force and the axis of the joint. The transverse axis of an intervertebral joint between two centra can be assumed to pass through the centre of the joint (Preuschoft 1976; Alexander 1985). The lever arms of the epaxial muscles can be estimated to be equal to the vertical distances between the centres of the joints and either the centres of the epaxial muscles or ligaments (Preuschoft 1976), or the line that connects the tips of the neural spines (Alexander 1985). Both methods lead to different absolute values, but to similar results if only the general pattern of torques along the vertebral column is of interest (Christian \& Preuschoft 1996). The lever arm $\mathrm{h}$ is estimated here as the distance between the centre of an intervertebral joint and the line connecting the tips of the neural spines.

The tensile force, $\mathrm{F}_{\mathrm{m}}$, of the epaxial muscles evokes a compressive force of the same magnitude between the vertebral centra (Preuschoft 1976; Alexander 1985; Christian \& Preuschoft 1996). This compressive force acts on the cartilage in the intervertebral joint. The muscle force, $F_{m}$, at a given position in the vertebral column can be calculated by $F_{m}=M / h$
(Preuschoft 1976; Alexander 1985; Christian \& Preuschoft 1996). $\mathrm{M}$ is the bending moment in the sagittal plane at the position investigated. The total compressive force, $\mathrm{F}$, acting on an intervertebral disc is the sum of two components: the muscle force, $\mathrm{F}_{\mathrm{m}}$, due to the bending moment, $\mathrm{M}$, and the weight force, $\mathrm{F}_{\mathrm{g}}$, of the fraction of the neck cranial to the position investigated multiplied by the cosine of the angle $\psi$ between the plane of the intervertebral joint and the horizontal plane (Fig. 1, see also Preuschoft 1976; Christian \& Preuschoft 1996; Christian \& Heinrich 1998; Christian 2002a). Thus:

$\mathrm{F}=\mathrm{F}_{\mathrm{m}}+\mathrm{F}_{\mathrm{g}} \cdot \cos \psi$

Forces different from static or quasistatic forces are neglected, assuming that forces due to accelerations or other activities are not predominant. This assumption seems reasonable for sauropods and has also been corroborated in studies on mammals with long necks (Christian 2002a), despite the occasional use of the head for combat in these animals. Under the assumption of equal safety factors, the highest regularly occurring stress on the cartilage between the vertebral centra, equivalent to the force $\mathrm{F}$ divided by the crosssectional area A of the intervertebral joint, should be constant along the neck. This assumption was also shown to be reasonable (Christian 2002a).

The cross-sectional area of each intervertebral joint is estimated by assuming an elliptical shape, with the transverse and dorsoventral diameters of the cranial surface of the adjacent vertebral centrum used as the major axes. In most sections of the neck, the caudal and cranial surfaces of contiguous vertebral centra are approximately proportional. In the cranial section of the neck, however, the diameter of the caudal end of the centrum cranial to the joint can be considerably larger than the cross-sectional area of the condyle of the adjacent centrum. Therefore, in contrast to the previous study by Christian \& Heinrich (1998) the estimates for the cross-sectional areas of the intervertebral joints are based here on the diameters of the condyles at the cranial ends of the centra and not on the dimensions of the caudal ends of the centra.

The volume of the head is estimated by assuming an ellipsoid shape, with the longitudinal, transverse and dorsoventral diameters of the head used as the major axes. This method was tested on horses and giraffes. In the giraffes, the head was reduced by the horns and the first $15 \mathrm{~cm}$ of the tapering

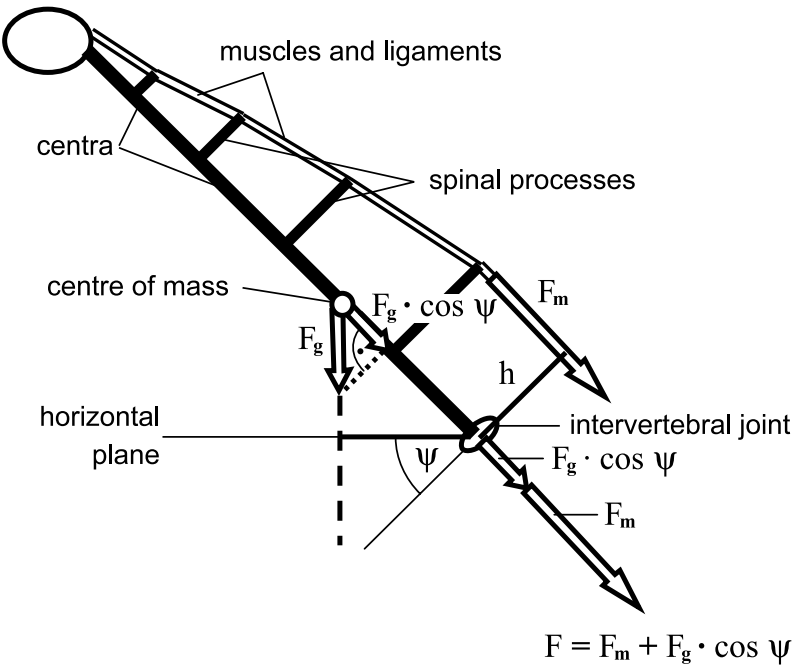

Fig 1. Determination of the compressive force acting in a joint between two vertebral centra. $\mathbf{F}_{\mathbf{m}}$ - muscle force; $\mathbf{F}_{\mathbf{g}}$ - weight force; $\mathbf{F}$ - total compressive force; $\boldsymbol{\psi}$ - angel between the plane of the intervertebral joint and the horizontal plane. For further explanation see the text. 
snout. In all animals tested, the mass of the head could be reproduced if the density was assumed to be between 0.8 and 0.85 kilograms per litre. A density below 1 is reasonable because of the nasal cavities in the skull and a slightly overestimated volume by assuming an ellipsoid shape of the head. In contrast to hoofed mammals, no large nasal cavities are found in the skull of Brachiosaurus. Therefore, the density of the head probably was slightly higher. The existence of cavities in the soft tissue, however, cannot be excluded. For the head of Brachiosaurus a density of approximately 0.9 kilograms per litre is assumed here. With a length of approximately $82 \mathrm{~cm}$, a height of $60 \mathrm{~cm}$ and a width of $44 \mathrm{~cm}$, a mass of roughly $100 \mathrm{~kg}$ was obtained for the head.

According to recent findings (e.g., Wedel 2003, 2005) the neck is assumed to be very lightly built. For the mass estimates, the neck is divided into segments, each starting and ending at the position of an intervertebral joint. The crosssectional areas of the segments are assumed to be of elliptical shape with $4 / 3$ times the maximum heights of the vertebrae used as dorsoventral diameters and $75 \%$ of this value as transverse diameters. Deformed vertebrae are reconstructed in order to determine the natural height. The first three segments of the neck are assumed to be more massive, because of muscle mass that was needed for head movements, and because of the comparatively higher fraction of the mass of supra- and infra-hyoidal structures, including oesophagus, larynx and trachea, in this part of the neck (see e.g. Dzemski, 2006, for an analysis of the mass distribution in the neck of the ostrich). The density of the neck, excluding the cavity inside the trachea, was estimated to be $2 / 3$ (about 0.67 ). Taking the air volume of the trachea into account would result in a considerably lower density. For this study, however, the segment masses and not volumes or densities are of importance, so that no estimates for the air volume of the trachea are conducted. The mass estimates are presented in Table 1 . The centre of mass of each segment is assumed to be halfway between the intervertebral joints and $20 \%$ of the height of the neural spine above the line that connects the midpoints of the intervertebral joints.

It appears unlikely that the neck could have been considerably lighter than estimated here. This model of the mass distribution is very different from the model used by Christian \& Heinrich (1998) with a very massive neck, except the most cranial neck section. In the model used here, the relation between the combined mass of the head and the first two neck sections and the section between the fourth and the eighth vertebra is about $25 \%$ compared with approximately $13 \%$ in the model employed by Christian and Heinrich (1998). In addition the estimates of the cross-sectional areas of the most cranial intervertebral joints are comparatively lower in the model used here, so that relative higher stress values are obtained for the most cranial neck section.

A comparison of the results obtained by using both models can be used for testing the robustness of the Preuschoft

\section{Table 1}

Basic data used for the calculations. m: segment mass; l: segment length; h: estimated lever arm of epaxial muscles and ligaments; A: cross-sectional area of the joint between the centra, measured at the base of the condyle.

\begin{tabular}{lrlll}
\hline Segment & $\begin{array}{l}\mathrm{m} \\
{[\mathrm{kg}]}\end{array}$ & $\begin{array}{l}\mathrm{l} \\
{[\mathrm{m}]}\end{array}$ & $\begin{array}{l}\mathrm{h} \\
{[\mathrm{m}]}\end{array}$ & $\begin{array}{l}\text { A } \\
{\left[\mathrm{cm}^{2}\right]}\end{array}$ \\
\hline head & 100 & & & \\
neck 1 & 60 & 0.42 & 0.22 & 64 \\
neck 2 & 50 & 0.40 & 0.22 & 122 \\
neck 3 & 75 & 0.60 & 0.24 & 146 \\
neck 4 & 91 & 0.72 & 0.27 & 190 \\
neck 5 & 132 & 0.83 & 0.31 & 225 \\
neck 6 & 219 & 0.86 & 0.38 & 297 \\
neck 7 & 328 & 0.96 & 0.45 & 346
\end{tabular}

method. Additionally, for a horizontal neck posture models with twice and half the neck mass, respectively, but constant values for the cross-sectional areas of the intervertebral joints and for the lever arms of epaxial muscles and ligaments are employed for testing the method.

To decide which neck posture was habitual in Brachiosaurus brancai, various hypothetical neck postures are tested (Fig. 2).

"Zygapophyseal alignment" models. "Zygapophyseal alignment" (ZA) positions are determined for two camels (Camelus bactrianus, one female Reg.-No. 7642 of Zoologisches Museum der Universität Hamburg, Germany, and one male, ZMFK 83.412 of the Forschungsmuseum Alexander Koenig, Bonn, Germany), two giraffes (Giraffa camelopardalis, both female, Reg.-No. 5834 of Zoologisches Museum der Universität Hamburg, Germany, and ZFMK 90.004 of the Forschungsmuseum Alexander Koenig, Bonn, Germany) and three ostriches (Struthio camelus, adult females, necks from the Straußenfarm Strukat, Germany).

In this study, ZA models for the necks of giraffes, camels, and ostriches are obtained by positioning the centres of the facets of the postzygapophyses above the centres of the prezygapophyses of the caudally adjacent vertebrae in side view. The midpoints of the lines connecting the cranial and caudal ends of the facets are used as the centres of the facets.

The reconstructed posture depends much on the thickness of the joint cartilage. In the ostrich, the thickness of the joint cartilage was determined by dissections. For the camel, the thickness of the intervertebral discs was determined from X-ray pictures of two living specimens (Tierpark Hagenbeck, Hamburg, and Zoo Magdeburg, both Germany). Based on the results for the camel and on results obtained from dissections of bovine and equine necks, the thickness of the intervertebral discs is assumed to be slightly higher in the giraffe than in the camel.

\section{Results}

\section{Reconstructions based on the Preuschoft method}

The hypothetical postures of the cranial $4.8 \mathrm{~m}$ of the neck are illustrated in Fig. 2. In the "vertical" posture the angle between the neck and the horizontal plane is $88^{\circ}$ instead of $90^{\circ}$ in order to prevent negative torques due to the location of the centres of mass of the segments slightly dorsal of the vertebral centra. The calculated stress on the cartilage between the vertebral centra is shown in Figs 3-5. Given a certain distribution of the mass along the head and neck, the estimated errors are around $15 \%$ due to possible errors in the estimates for the lever arms of the epaxial muscles and for the cross-sectional areas of the intervertebral joints.

With a straight neck, the stress increases towards the base of the neck in all hypothetical postures, except the vertical posture. In a vertical posture the stress on the intervertebral cartilage is more or less constant along the examined section of the neck. In a vertical posture, however, the stress is comparatively high in the joint between the axis and the third vertebra. A nearly constant stress can also be obtained with an inclined neck that is flexed ventrally at its distal end (Fig. 2B). In this posture, the stress is comparatively low in the joints 


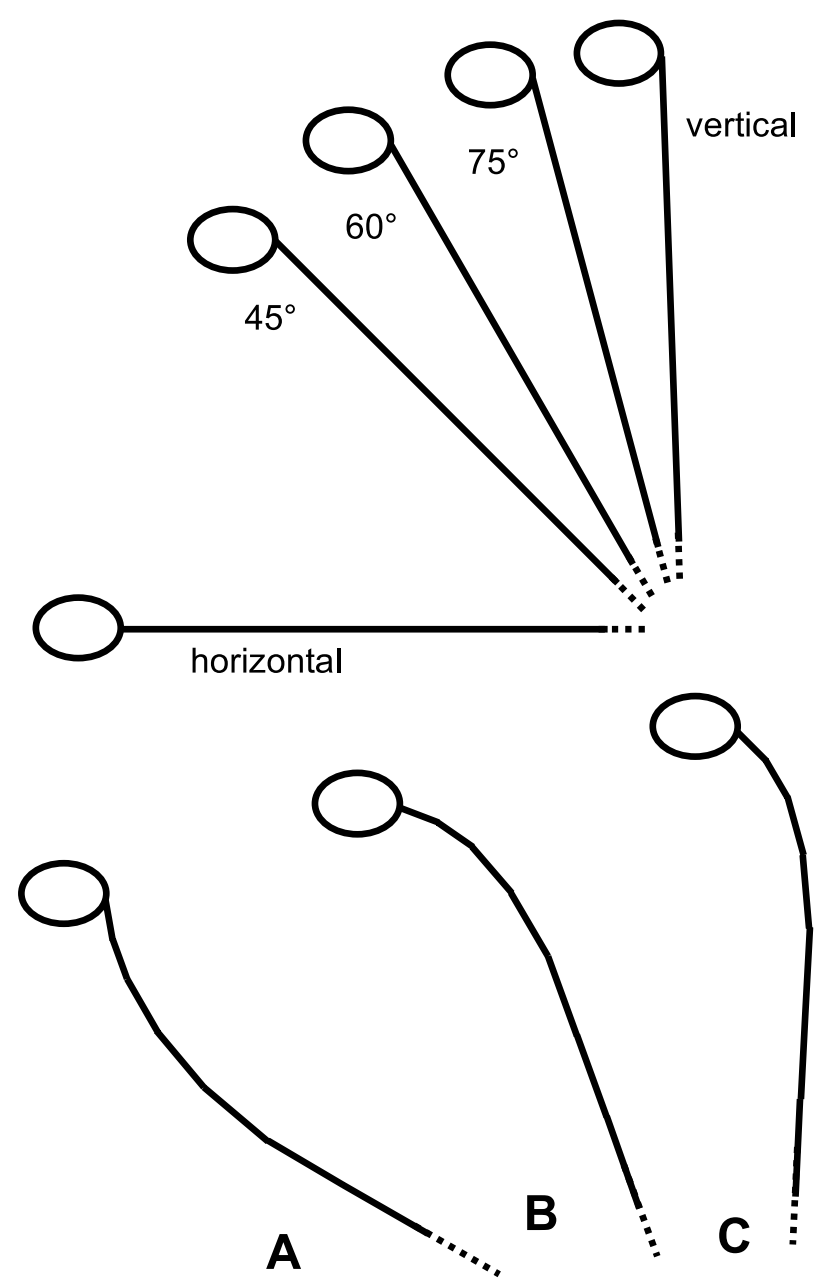

Fig 2. Hypothetical neck postures for Brachiosaurus brancai Janensch, 1914.

close to the head. Neither a more inclined neck posture with the cranial section flexed dorsally (Fig. 2A) nor a S-shaped neck posture with a slight backward inclination of the middle section of the neck (Fig. 2C) yield approximately constant values for the stress. In order to compare the variation of

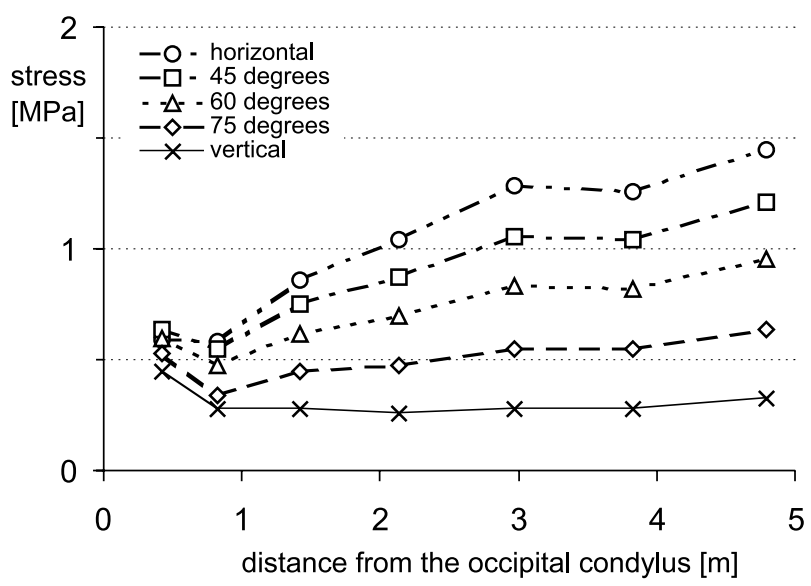

Fig 3. Stress on the intervertebral joints along the cranial 4.8 meters of the neck of Brachiosaurus brancai Janensch, 1914 calculated for the hypothetical straight neck postures presented in Fig. 2.

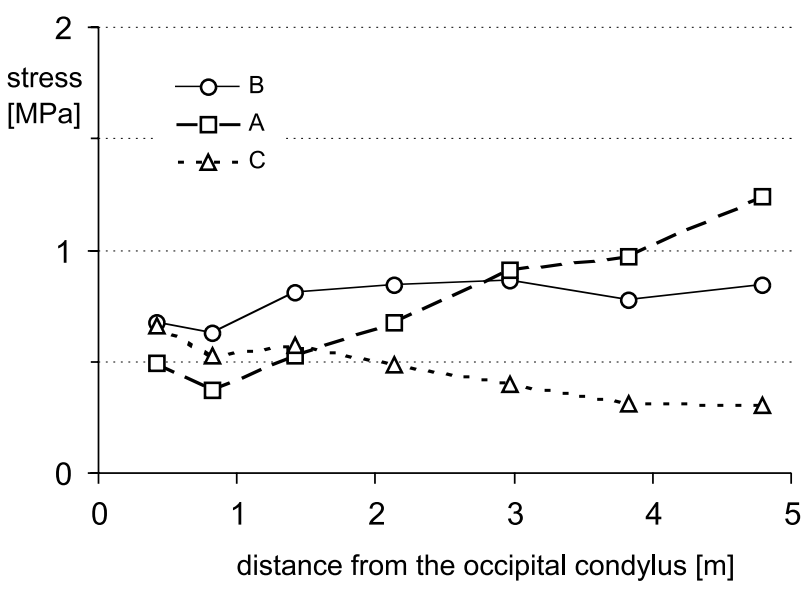

Fig 4. Stress on the intervertebral joints along the cranial 4.8 meters of the neck of Brachiosaurus brancai Janensch, 1914 calculated for the hypothetical curved neck postures presented in Fig. 2.

the stress values, the standard deviations divided by the mean values for all neck postures tested are presented in Table 2.

Although both, a vertical neck posture and a slightly inclined posture with ventral flexion in the cranial neck section, yield more or less constant stress values, the inclined posture appears to be more reasonable. The analysis is based on the assumption that static or quasistatic stress is predominant along the neck. This assumption is reasonable for most parts of the neck, but not for the most cranial neck section because of additional forces that have to be expected for positioning and moving the head relative to the neck during feeding (see also Preuschoft \& Fritz (1977) for horses). Therefore, in a static situation without such extra forces, a comparatively low stress has to be expected for the most cranial joints. This expectation fits the results obtained for an inclined neck posture with a ventral flexion at the distal end. Therefore, with the Preuschoft method the elevation of the neck is slightly overestimated if the intervertebral joints close to the head are included in the

Table 2

Standard deviations of stress values, SD, divided by mean stress, MS, for all seven joints between the second and the eighth vertebral centra, SD/MS [2-8], and for the joints between the fourth and the ninth centra, SD/MS [4-8]. Horizontal $2 \times, 0.5 \times$ : horizontal posture with double or half the neck mass, respectively. For the other postures see Fig. 2.

\begin{tabular}{lll}
\hline Posture & SD/MS [2-8] & SD/MS [4-8] \\
\hline horizontal & 0.34 & 0.19 \\
Horizontal 2× & 0.46 & 0.27 \\
horizontal 0.5 & 0.21 & 0.11 \\
inclined 45 & 0.28 & 0.18 \\
inclined $60^{\circ}$ & 0.23 & 0.17 \\
inclined $75^{\circ}$ & 0.19 & 0.14 \\
vertical $\left(88^{\circ}\right)$ & 0.22 & 0.09 \\
posture A & 0.42 & 0.32 \\
posture B & $\mathbf{0 . 1 2}$ & $\mathbf{0 . 0 4}$ \\
posture C & 0.29 & 0.28
\end{tabular}




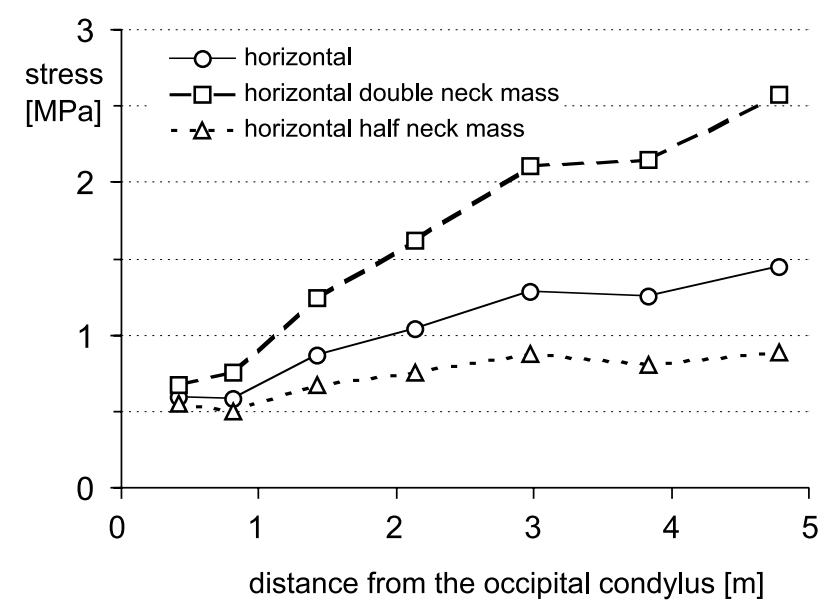

Fig 5. Stress on the intervertebral joints along the cranial 4.8 meters of the neck of Brachiosaurus brancai Janensch, 1914 calculated for a horizontal neck posture compared with models with double and half the neck mass, respectively.

analysis. In specimen S I a marked increase of the heights of the neural spines can be observed between the sixth and seventh vertebra, even if the deformation of the vertebrae is taken into account. This observation also indicates a ventral flexion of the portion of the neck cranial to the seventh vertebra (see also Wedel et al. (2000) for a similar observation in Sauroposeidon).

Fig. 5 illustrates the effect of differences in the mass distribution along head and neck. Compared to the model described above, the relation between head and neck mass was increased or reduced by a factor of two, respectively. With decreasing neck mass, the variation of stress along the neck also decreases. However, the model employed here is already based on the assumption of a comparatively light neck. The head and the cranial neck sections cannot have been much heavier than estimated here. In order to obtain constant stress values in a horizontal neck posture either an unrealistic thin neck with the vertebrae just fitting into the skin or a total density of the neck, including the air volume inside the trachea, below 0.3 kilograms per litre would have to be assumed. These assumptions do not appear to be reasonable.

\section{$\mathrm{ZA}$ models tested in extant vertebrates with a long neck}

For ostriches, camels and giraffes postures of the neck with the facets of the postzygapophyses centred above the prezygapophyses of the caudally adjacent vertebrae (ZA postures) are illustrated in Figs 6 and 7. In contrast to the findings of Stevens \& Parrish $(1999,2005 a, 2005 b)$ the reconstructed neck postures are considerably lower than the habitual postures during standing, especially in the ostrich and the camel. In the giraffe it is more difficult to determine the orientation of the first dorsal

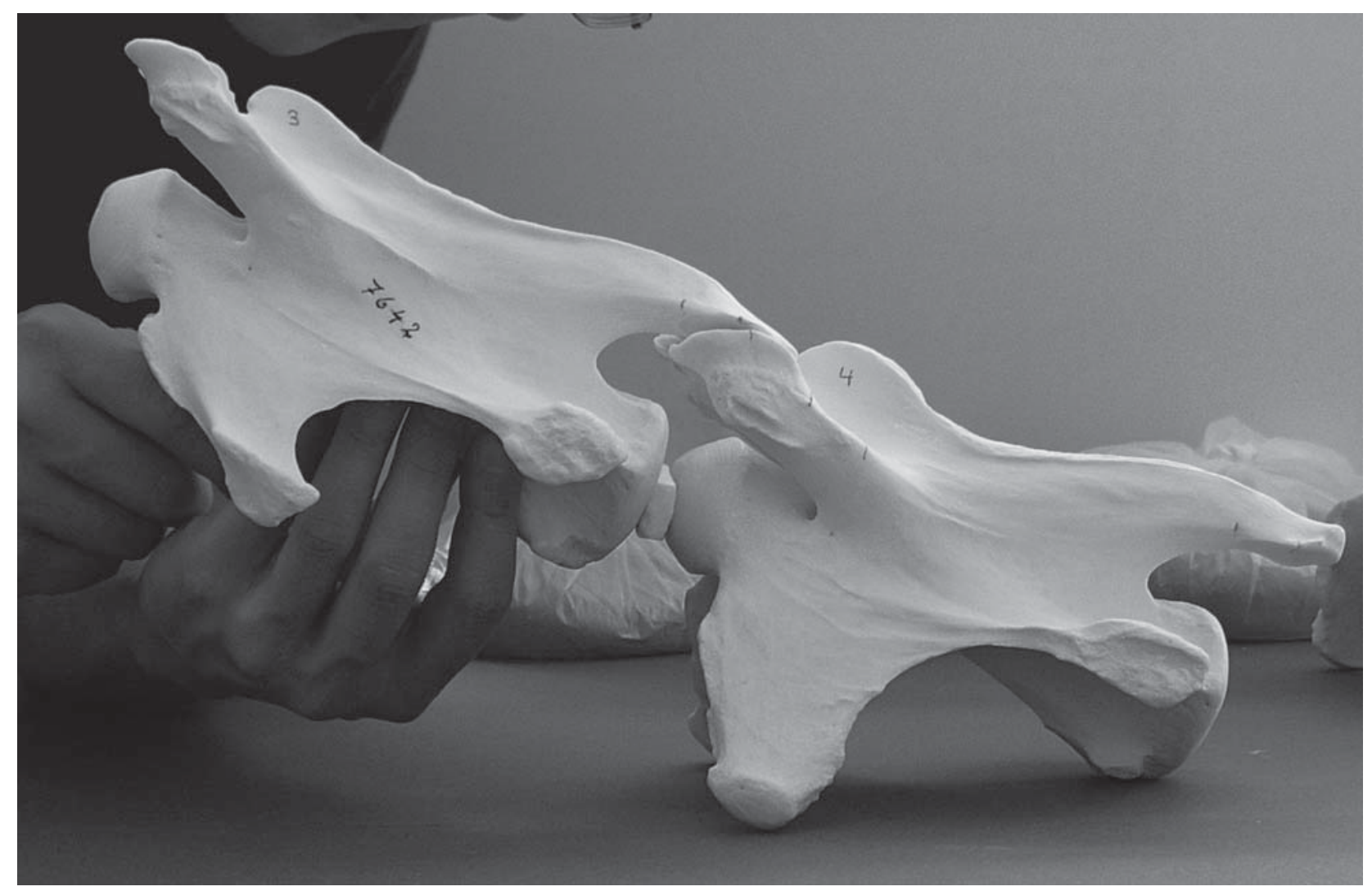

Fig 6. The cervical vertebrae 3 and 4 of a camel in "zygapophyseal alignment" (ZA) position. 


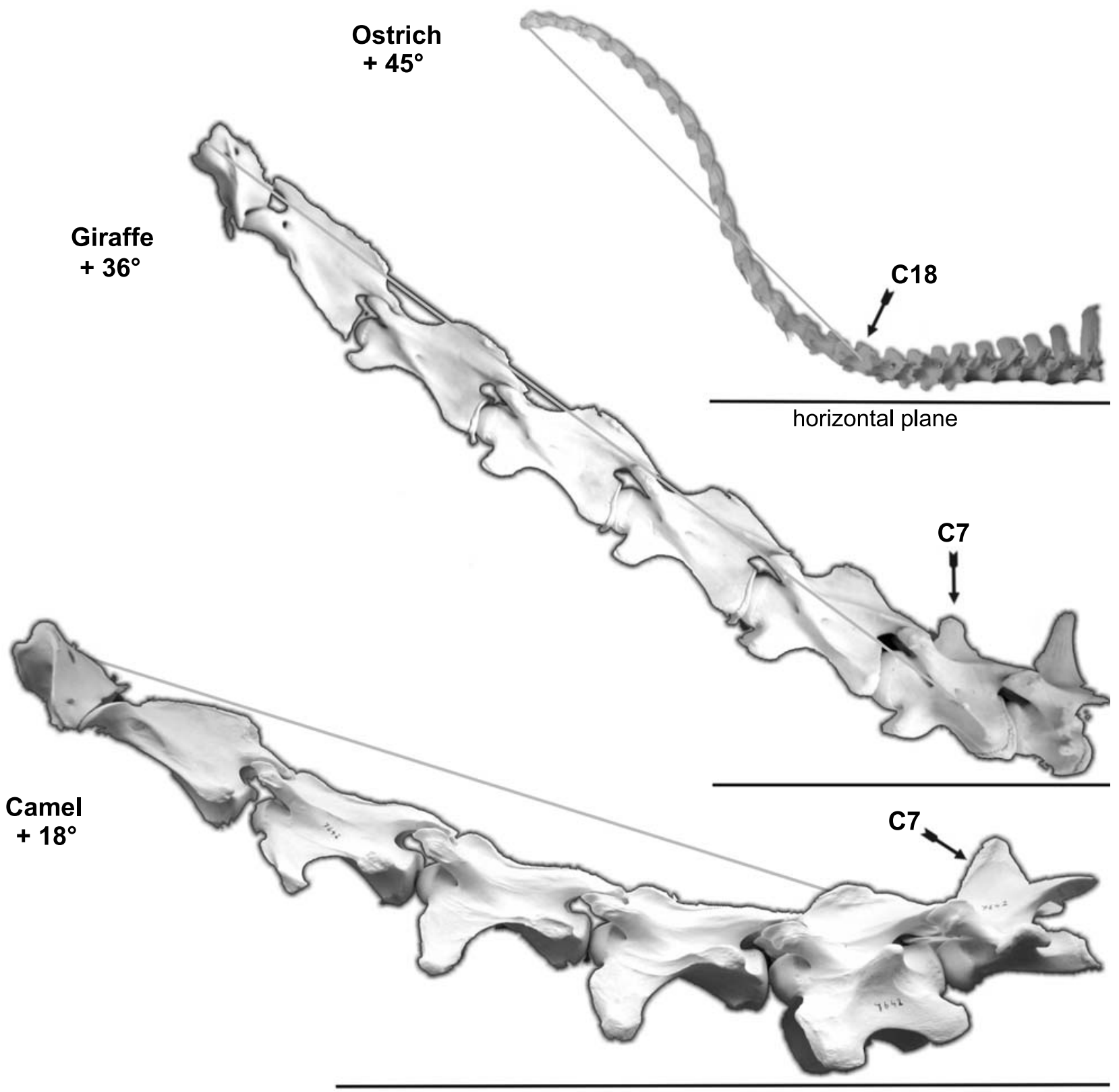

Fig 7. "Zygapophyseal alignment" (ZA) positions for the necks of an ostrich, a camel, and a giraffe.

vertebra than in the other species studied. An increased angle between the first dorsal vertebra and the horizontal plane would yield a more vertical position of the neck. The position of the first dorsal vertebra chosen here, however, was derived from pictures of standing giraffes with the neck kept in a habitual posture (Dzemski 2005) and appears more appropriate than the orientation chosen by Stevens \& Parrish (2005a). In the camel and the ostrich, aside from the inclination also the form of the ZA posture considerably deviates from the habitual neck posture during standing.

Whereas the ZA postures do not match the habitual positions of the necks during standing, they correspond better to the postures observed during locomotion (for a detailed analysis of the neck posture in giraffes see Dzemski 2005).

\section{Discussion}

\section{Comparison of the results obtained by employing different methods}

In the following the results for the habitual neck posture of Brachiosaurus brancai obtained by employing different methods are summarised together with a discussion of the reliability of the methods.

Preuschoft method. The method was already shown to be a robust and reliable instrument for the reconstruction of the habitual neck posture of long-necked terrestrial vertebrates by examining the necks of two large and long-necked recent mammals, Giraffa camelopardalis and Camelus sp. (Christian 2002a, 2002b). Applied to the whole ver- 
tebral column, the method was also shown to yield reliable results for body posture among a variety of extinct and extant vertebrate species (Christian \& Preuschoft 1996). The robustness of this method is corroborated here by yielding a result similar to Christian \& Heinrich (1998) with a model for the distribution of head and neck mass that differs considerably from the model employed by Christian \& Heinrich (1998). It is demonstrated here, that only extreme variations in the assumed mass distribution along the head and neck lead to considerable differences in the reconstructed neck posture.

A bias in the results due to forces acting along the cervical ribs cannot be excluded. As outlined by Janensch (1950a), force is needed to bend the two rods that are formed by the overlapping cervical ribs. According to Frey \& Martin (1997) torques due to the weight of the neck were primarily counteracted by compressive forces in these structures. A moderate contribution of the cervical ribs for resisting bending moments in a habitual neck posture cannot be excluded. However, a horizontal neck posture with the cervical ribs functioning as the major structures for counteracting forces due to bending moments is very unlikely because of several reasons:

In a horizontal neck posture, the diameters of the cervical ribs do not increase towards the caudal end of the neck in the same way as the bending moments do. Even if an overlap of several cervical ribs is taken into account, the combined strength of the cervical ribs at the positions of the intervertebral joints does not markedly increase or even decreases behind the $10^{\text {th }}$ vertebra.

The last cervical rib, of the $13^{\text {th }}$ vertebra, is short and not directed backwards. The two rods formed by the cervical ribs are interrupted here so that compressive forces cannot be exchanged between cervical ribs in this part of the vertebral column. If the cervical ribs were major structures for counteracting torques due to gravity, a tremendous increase of the surface areas of the intervertebral joints would be needed at the base of the neck in order to sustain the additional compressive forces. Such a marked increase in the diameters of the intervertebral joints is not visible.

At the most caudal neck vertebrae, the cross-sectional areas of the intervertebral joints are by a factor of roughly 70 or 80 higher than the combined diameters of all cervical ribs at the positions of the intervertebral joints. Even if the ultimate compressive stress is roughly ten times higher in bone than in joint cartilage (Yamada 1973) this comparison indicates, that the intervertebral joints and not the cervical ribs were the major structures for resisting compressive forces. Furthermore, it cannot be expected that the cervical ribs were always loaded in an ideal way, that is perfectly axial. During bending, the maximum stress that can be sustained by a bone is much lower than during compression with an axial load.

Maximum compressive load on the cervical ribs was only possible during maximum ventral flexion of the neck because flexion of the neck in dorsal or lateral direction would have considerably reduced the bracing effect of the cervical ribs of both sides or of one side of the neck, respectively, whereas torques due to gravity would have remained high.

It appears more likely that the cervical ribs of Brachiosaurus were used primarily for transmitting tensile forces similar to some species of birds and sauropods with shorter cervical ribs (Wedel \& Sanders 2002). With long structures for transmitting forces, the muscle mass was shifted caudally, so that the weight of the neck, especially of the cranial and middle section, was reduced. However, cervical ribs probably inhibited lateral movements of the neck (Janensch 1950a; Upchurch \& Barrett 2000) as well as extreme ventral flexion.

With the refined model employed here an inclined position of the neck of Brachiosaurus brancai is proposed with an angle of approximately $70^{\circ}$ between the middle section of the neck and the horizontal plane and a marked ventral flexion in the distal part of the neck, whereas Christian \& Heinrich (1998) obtained a fully vertical neck posture. In this study, the calculations are based on the assumption of a very light neck. A further reduction of the estimated neck mass would result in a lower position of the neck. However, as discussed above, it appears unlikely that the neck mass is considerably overestimated here. For the habitual position of the neck at rest, an inclination of the middle section of the neck considerably below $60^{\circ}$ is unlikely. A more or less horizontal habitual neck posture has to be rejected.

$\mathrm{ZA}$ models. In the models used by Stevens \& Parrish $(1999,2005 a, 2005 b)$ the facets of the preand postzygapophyses are aligned and centred, and simultaneously, the margins of "cotyle" and "condyle" of each intervertebral joint are parallel (Stevens \& Parrish 2005a). In the extant mammals studied here, however, the margins of the intervertebral joints are not always parallel if the facets of the pre- and postzygapophyses are centred. In the illustration of the neck of a giraffe in the position with optimal articulation between the neck vertebrae ("neutral pose") by Stevens \& Parrish (2005a) at least the margins of the cotyle of cervical 7 and the condyle of dorsal 1 are not parallel, either. In extant vertebrates as well as in sauropods, in side view the margins of the cotyles and condyles of the vertebral centra are frequently neither linear nor does the form of the margin of the cotyle always match the form of the margin of the condyle. A wedge-shape of a centrum in side view is not conclusive either, e.g. because of the non-linear form of the margins of cotyles and condyles in side view. 
In the giraffe, the centrum of the first dorsal vertebra is clearly wedge-shaped in side view (see Fig. 7), but the wedge is pointing downward as expected for a marked ventral flexion instead of the dorsal flexion that is observed in this region of the vertebral column.

According to Preuschoft et al. (1988), the pronounced intra-vitam adaptation to a lordotic curvature in trained macaque monkeys results exclusively from the wedge-shaped intervertebral discs, while the vertebrae remain unchanged. Similar results were obtained by Abitbol (1987) for young children at the time of learning to walk.

Because of the reasons outlined above, unequivocal results cannot be obtained by using the margins of the cotyles and condyles at the intervertebral joints for reconstructing neck postures that are based on an optimal articulation between the neck vertebrae. Therefore, in this study ZA models for the necks of giraffes, camels, and ostriches were obtained only by positioning the centres of the facets of the postzygapophyses above the centres of the prezygapophyses of the caudally adjacent vertebrae (see methods). Even this apparently uncomplicated method did not yield perfectly unequivocal results, because slight differences were obtained by centring either the midpoints of the lines connecting the cranial and caudal ends of the facets or by centring the midpoints of the surface areas of the facets. In one case (camel) the length of the prezygapophyses differed considerably between both sides of the same vertebra.

It appears reasonable to expect an overlap of the zygapophyseal facets in a habitual neck posture. However, if different neck postures are frequently employed by an animal, the ZA position of the neck cannot be expected to match the habitual posture during standing. If, e.g., the neck is kept high during standing but low during feeding the neck posture at rest cannot be expected to be in the middle of the range of possible neck excursions. In this case, the overlap of the zygapophyseal facets should be maximal somewhere close to the middle of the range of possible neck excursions rather than in the habitual posture. The results for extant vertebrates presented here show that the position as well as the form of the neck in the ZA posture with the facets of the postzygapophyses centred above the facets of the prezygapophyses can deviate considerably from the habitual neck posture at rest which living animals really assume. However, the ZA posture appears to be suitable for roughly estimating the neck posture during locomotion. During locomotion, the forces acting in the neck very probably are higher than at rest. Therefore, an optimal articulation of the zygapophyses during locomotion rather than at rest is not surprising. In the extant vertebrates studied, the inclination of the neck, represented by the line between the head and the intervertebral joint at the neck-trunk tran- sition, was roughly $20^{\circ}$ lower in the ZA model and during locomotion if compared to the position at rest.

For Brachiosaurus, the ZA model by Stevens \& Parrish (2005a, 2005b) yields a slightly ventral flexion of the neck. In contrast to Stevens \& Parrish (2005a, 2005b) it is not likely that the height of the vertebral column at the shoulders is overestimated in the exhibited skeleton at the Museum für Naturkunde der Humboldt-Universität zu Berlin since the limbs have to be straightened (Christian et al. 1999). With straighter limbs the position of the pectoral girdle has to be changed as well in order to prevent constraints for limb movements during locomotion. The position of the shoulder joints has to be shifted backwards and downwards relative to the ribs so that the scapula is pointing more upwards. These considerations are in accordance with the strengths of the dorsal ribs. Only the first three ribs are very strong. With the alterations proposed above, the angle between the first dorsal vertebra and the horizontal plane is around $20^{\circ}$.

In Brachiosaurus brancai the zygapophyses of the proximal section of the neck and the most cranial vertebrae of the trunk are not preserved. Therefore, a ZA model cannot be obtained for this part of the neck, anyway.

From the evidence that is put forward here, the neck posture of Brachiosaurus brancai that is obtained by employing the Preuschoft method is not in contrast to the articulation of the neck vertebrae. During locomotion, the neck probably was lowered by approximately $20^{\circ}$.

Internalstructure of the vertebral centra. According to a thorough mechanical study by Berman \& Rothschild (2005) the internal structure of the vertebral centra indicates a predominance of bending moments rather than compressive forces along the neck. The authors conclude that the neck was kept horizontally in Brachiosaurus and other sauropods with long necks. However, bending moments along the neck are high even if the neck posture deviates by only $20^{\circ}$ from the vertical. The fact, that neck vertebrae are compact only in sauropods with comparatively short necks, like Camarasaurus, is not surprising because of the steep increase of muscle, ligament and joint forces and moments with increasing neck length, even in nonhorizontal positions. Berman \& Rothschild (2005) focus on the vertebral centra, but the strength of a vertebra does also depend on the shape and structure of the processes, especially if bending moments are considered.

The study by Berman \& Rothschild (2005) shows that the neck of Brachiosaurus was not frequently involved in strenuous activities, as it is proposed here (see methods).

Zygapophyses and cervical ribs. As outlined by Janensch (1950a) in most parts of the neck 
lateral flexion is constrained by the cervical ribs as well as by the orientation, position and the curved shape of the zygapophyses. The reduction of the vertebral ribs at the base of the neck and the comparatively large and broad zygapophyses in the most cranial neck section indicate that the neck was more flexible at both ends of the neck than in the long middle portion, especially in lateral directions. These findings are at least not in contrast to the idea of browsing at great heights.

Skull and Dentition. The reconstruction of the feeding mechanism of Brachiosaurus by Upchurch \& Barrett (2000) is in accordance with the assumption of browsing at great heights.

Dimensions of the inner ear. According to Gunga \& Kirsch (2001) the dimensions of the inner ear, especially of the semicircular canals, indicate that Brachiosaurus brancai employed dorsoventral neck movements with low frequency and lateral movements with a higher frequency. These findings are in accordance with the assumption of browsing at different heights.

Blood pressure. A position of the head high above the heart results in extreme stress on the cardiovascular system. In order to reduce this stress it appears likely that the head was not kept permanently close to the highest position possible (Hohnke 1973; Seymour 1976; Dodson 1990; Badeer \& Hicks 1996; Seymour \& Lillywhite 2000). With a ventral flexion in the distal neck section, an inclination of the middle section of the neck between $60^{\circ}$ and $70^{\circ}$ and an inclination of the most proximal neck section of about $30^{\circ}$, the height of the head above the heart was reduced by more than two meters if compared to a fully vertical position of the neck. According to the findings presented here, the head was kept even lower during locomotion.

Ecology. It can be expected that different sauropods of the same habitat employed different feeding strategies (e.g., Dodson 1990). It appears reasonable to assume that some species browsed at great heights.

Overall body design. The overall body design of Brachiosaurus brancai with an apparently short tail and forelimbs that were longer than the hindlimbs and not very forceful (Christiansen 1997) indicates an elevated position of the neck (e.g., Christian 2002a). The height of the head was increased by the length of the forelimbs. Compared to a sauropod with a horizontal neck posture, less weight was carried by the forelimbs of Brachiosaurus brancai. Sideways movements of a horizontal neck evoke varying forces in the limbs, and a very long tail is necessary to counteract these neck movements. With a more vertical neck, lateral neck excursions are reduced and the centre of mass of the body is shifted backwards, so that the hindlimbs are loaded much more than the forelimbs.

\section{Feeding strategy}

With the evidence obtained by different methods and considering the cogency of each method, it is possible to draw a conclusive picture of the feeding strategy of Brachiosaurus brancai.

The shape of the neck probably was similar to the reconstruction by Janensch (1950b) with a ventral flexion in the cranial section of the neck, an approximately straight middle section and a moderate dorsiflexion at the base of the neck and at the foremost section of the thorax (Fig. 8). Due to the elevation of the cranial part of the thorax the first dorsal vertebrae already formed an angle of approximately $20^{\circ}$ with the horizontal plane. In the habitual posture during standing, the angle between the middle section of the neck and the horizontal plane probably was around $60^{\circ}$ or $70^{\circ}$, slightly higher than reconstructed by Janensch (1950b). During locomotion the whole neck was kept in a lower position with its inclination reduced by roughly $20^{\circ}$ if compared with the position at rest. The height of the head was seven or eight meters above the heart at rest and possibly around five meters above the heart during locomotion. Therefore, the stress on the cardiovascular system was considerably less than with a fully vertical position of the neck.

During feeding movements of the head relative to the neck as well as movements in the cranial part of the neck could be performed without much altering the height of the centre of gravity of the neck. With slow dorsoventral movements of the whole neck pronounced changes in the feeding height were possible. Sideways movements without altering the height of the centre of mass of the neck were performed by lateral flexion at the base

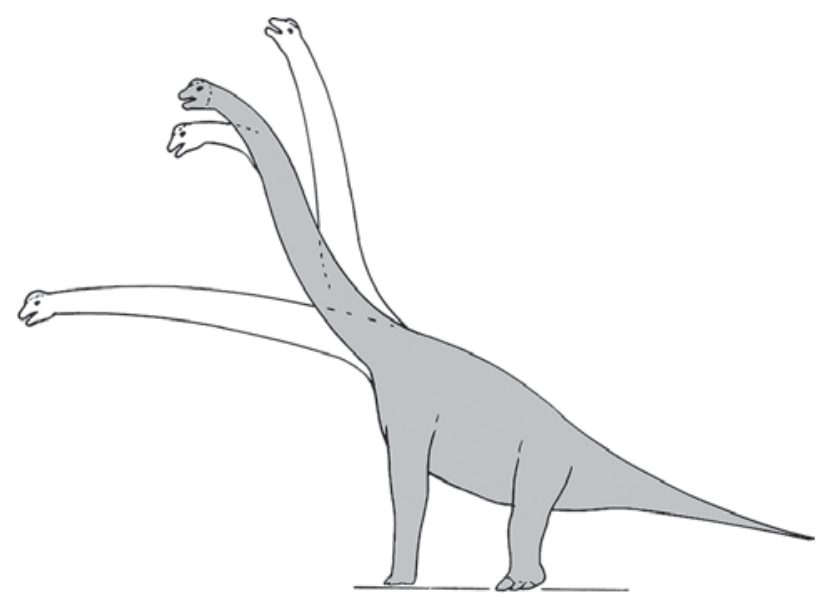

Fig 8. The reconstructed habitual neck posture of Brachiosaurus brancai Janensch, 1914 at rest (shaded) and possible postures during feeding. 
of the neck. With these neck movements the very long neck of Brachiosaurus brancai was both, a means for browsing at great heights and a means for increasing the feeding volume without moving the body.

\section{Acknowledgements}

Skeletal elements of Brachiosaurus brancai were examined at the Museum für Naturkunde der Humboldt-Universität zu Berlin, Germany. We are especially obliged to W. D. Heinrich for information about the head skeleton. X-ray pictures of the necks of camels were provided by the Tierpark Hagenbeck and the Zoo Magdeburg. Neck skeletons were made available by the Zoologisches Museum der Universität Hamburg and the Forschungsmuseum Alexander Koenig, Bonn. Necks of ostriches were supplied by the Straußenfarm Strukat. We thank J.-Th. Möller and G. Christian for assistance in collecting the data. We thank D. M. Henderson and H. Preuschoft for reviews. This is contribution number 30 of the DFG research unit "Biology of the Sauropod Dinosaurs".

\section{References}

Abitbol, M. 1987. Evolution of the sacrum in hominoids. American Journal of Physical Anthropology 74: 65-81.

Alexander, R. McN. 1985. Mechanics of posture and gait of some large dinosaurs. - Zoological Journal of the Linnean Society 83 (1): 1-25.

- 1989. Dynamics of dinosaurs and other extinct giants. 167 pp., Columbia University Press, New York.

Badeer, H. S. \& Hicks, J. W. 1996. Circulation to the head of Barosaurus revised: theoretical considerations. - Comparative Biochemistry \& Physiology A114: 197-203.

Bakker, R. 1987. The dinosaur heresies. A revolutionary view of dinosaurs. 481pp., Longman, Harlow.

Berman, D. S. \& Rothschild, B. M. 2005. Neck Posture of Sauropods Determined Using Radiological Imaging to Reveal Three-Dimensional Structure of Cervical Vertebrae. In Tidwell, V. \& Carpenter, K. (eds). Thunder Lizards: The Sauropodomorph Dinosaurs: 233-247, Indiana University Press, Bloomington.

Christian, A. 2002a. Neck posture and overall body design in sauropods. - Mitteilungen aus dem Museum für Naturkunde in Berlin, Geowissenschaftliche Reihe 5: 269-279.

- 2002b. Posture and mechanics of prosauropod and sauropod dinosaurs. - Schriftenreihe der Deutschen Geologischen Gesellschaft, Programme und Abstracts 21: 93.

- 2004. Reconstruction of the neck posture in sauropods. In M. Evans, M. \& Forrest, R. (eds). 52 ${ }^{\text {nd }}$ Symposium of Vertebrate Palaeontology and Comparative Anatomy: P9, Abstracts, Leicester, University of Leicester.

Christian, A. \& Heinrich, W.-D. 1998. The neck posture of Brachiosaurus brancai. - Mitteilungen aus dem Museum für Naturkunde in Berlin, Geowissenschaftliche Reihe 1: 73-80.

Christian, A. \& Preuschoft, H. 1996. Deducing the body posture of extinct large vertebrates from the shape of the vertebral column. - Palaeontology 39 (4): 801-812.

Christiansen, P. 1997. Locomotion in sauropod dinosaurs. Gaia 14: 45-75.

Dzemski, G. 2005. Funktionsmorphologische Betrachtung der Halsstellung bei Zoogiraffen. - Der Zoologische Garten 3: $189-201$.

- 2006. Funktionsmorphologische Analysen langer Hälse bei rezenten terrestrischen Wirbeltieren zur Rekonstruk- tion der Stellung und Beweglichkeit langer Hälse prähistorischer Tiere. 140 pp., Dissertation, Universität Flensburg.

Dodson, P. 1990. Sauropod Paleoecology. In Weishampel, D. B., Dodson, P. \& Osmólska, H. (eds). The Dinosauria: 402-407, University of California Press, Berkeley, Los Angeles and London.

Farlow, J. O. 1987. Speculations about the diet and digestive physiology of herbivorous dinosaurs. - Paleobiology 13: $60-72$.

Frey, E. \& Martin, J. 1997. Long necks of Sauropods. In Currie, P. J. \& Padian, K. (eds). Encyclopedia of Dinosaurs: 406-409, Academic Press, San Diego.

Gunga, H.-C. \& Kirsch, K. 2001. Von Hochleistungsherzen und wackeligen Hälsen. - Forschung 2-3: 4-9.

Gunga, H.-C., Kirsch, K. A., Baartz, F., Röcker, L., Heinrich, W.-D., Lisowski, W., Wiedemann, A. \& Albertz, J. 1995. New data on the dimensions of Brachiosaurus brancai and their physiological implications. - Naturwissenschaften 82(4): 189-192.

Gunga, H.-C., Kirsch, K., Rittweger, J., Röcker, L., Clarke, A., Albertz, J., Wiedemann, A. Mokry, S., Suthau, T., Wehr, A., Heinrich, W.-D. \& Schultze, H.-P. 1999. Body size and body volume distribution in two sauropods from the Upper Jurassic of Tendaguru (Tanzania). - Mitteilungen aus dem Museum für Naturkunde in Berlin, Geowissenschaftliche Reihe 2: 91-102.

Henderson, D. M. 1999. Estimating the masses and centers of mass of extinct animals by 3-D mathematical slicing. Paleobiology 25: 88-106.

- 2004. Tipsy punters: sauropod dinosaur pneumaticity, buoyancy and aquatic habits. - Proceedings of The Royal Society London B (Supplement) 271: 180-183.

Hohnke, L. A. 1973. Haemodynamics in the Sauropoda. Nature 244: 309-310.

Janensch, W. 1914a. Bericht über den Verlauf der Tendaguru-Expedition.- Archiv für Biontologie III (1): 15-58.

- 1914b. Die Gliederung der Tendaguru-Schichten im Tendaguru-Gebiet und die Entstehung der Saurierlagerstätten. - Archiv für Biontologie III (3): 226-261.

- 1938. Brachiosaurus, der größte sauropode Dinosaurier aus dem oberen Jura von Deutsch-Ostafrika. - Forschungen und Fortschritte 14 (12): 140-141.

- 1950a. Die Wirbelsäule von Brachiosaurus brancai. - Palaeontographica, Supplement VII, 1. Reihe, Teil 3, Lieferung 2: 27-92.

- 1950b. Die Skelettrekonstruktion von Brachiosaurus brancai. - Palaeontographica, Supplement VII, 1. Reihe, Teil 3, Lieferung 2: 95-103.

Martin, J. 1987. Mobility and feeding of Cetiosaurus (Saurischia: Sauropoda) - why the long neck? In Curry, P. J. \& Koster, E. H. (eds). $4^{\text {th }}$ Symp. Mesozoic Terrestrial Ecosystems. Short Paper: 154-159, Tyrell Museum of Paleontology, Drumheller, Alberta.

McIntosh, P. 1990. Sauropod Paleoecology. In Weishampel, D. B., Dodson, P. \& Osmólska, H. (eds). The Dinosauria: 345-401, University of California Press, Berkeley, Los Angeles and London.

Paul, G. S. 1987. The science and art of restoring the life appearance of dinosaurs and their relatives. In Czerkas, S. J. \& Olsen, E. C. (eds). Dinosaurs past and present, vol. 2: 5-49, Natural History Museum of Los Angeles County, Los Angeles.

- 1988. The brachiosaur giants of the Morrison and Tendaguru with a description of a new subgenus, Giraffatitan, and a comparison of the word's largest dinosaurs. - Hunteria 2 (3): 1-14.

Preuschoft, H. 1976. Funktionelle Anpassung evoluierender Systeme. - Aufsätze und Reden der Senckenbergischen Naturforschenden Gesellschaft 28: 98-117.

Preuschoft, H. \& Fritz, M. 1977. Mechanische Beanspruchung im Bewegungsapparat von Springpferden. - Fortschritte der Zoologie 24: 75-98. 
Preuschoft, H., Hayama, S. \& Günther, M. M. 1988. Curvature of the lumbar spine as a consequence of mechanical necessities in Japanese macaques trained for bipedalism. - Folia primatologica 50: 42-58.

Seebacher, F. 2001. A new method to calculate allometric length-mass relationships of dinosaurs. - Journal of vertebrate Paleontology 21 (1): 51-60.

Sereno, P. C. \& Wilson, J. A. 2005. Structure and evolution of a sauropod tooth battery. In Wilson, J. A. \& Curry-Rers, K. (eds). The Sauropods: Evolution and Paleobiology: 157-177, University of California Press.

Seymour, R. S. 1976. Dinosaurs, endothermy and blood pressure. - Nature 262: 207-208.

Seymour, R. S. \& Lillywhite, H. B. 2000. Hearts, neck posture, and metabolic intensity of sauropod dinosaurs. Proceedings of the Royal Society of London 267 (B): 1883-1887.

Stevens, K. A. \& Parrish, M. J. 1999. Neck posture and feeding habits of two Jurassic sauropod dinosaurs. - Science 284: $798-800$.

- 2005a. Digital Reconstructions of Sauropod Dinosaurs and Implications for Feeding. In Wilson, J. A. \& CurryRogers, K. (eds). The Sauropods: Evolution and Paleobiology: 178-200, University of California Press.

- 2005b. Neck posture, Dentition and Feeding Strategies in Jurassic Sauropod Dinosaurs. In Tidwell, V. \& Car- penter, K. (eds). Thunder Lizards: The Sauropodomorph Dinosaurs: 212-232, Indiana University Press, Bloomington.

Upchurch, P. \& Barrett, P. M. 2000. The evolution of sauropod feeding mechanisms. In Sues, H.-D. (ed.). Evolution of herbivory in terrestrial vertebrates: perspectives from the fossil record: 79-122, Cambridge University Press, Cambridge, U.K.

Wedel, M.J. 2003. The evolution of vertebral pneumacity in sauropod dinosaurs. - Journal of Vertebrate Paleontology 23: $344-357$.

- 2005. Postcranial skeletal pneumaticity in sauropods and its implications for mass estimates. In Wilson, J. A. \& Curry-Rogers, K. (eds). The Sauropods: Evolution and Paleobiology: 201-228, University of California Press.

Wedel, M. J., Cifelli, R. I. \& Sanders, R. K. 2000. Sauropseidon proteles, a new sauropod from the Early Creatceous of Oklahoma. - Journal of Vertebrate Paleontology 20: 109-114.

Wedel, M. J. \& Sanders, R. K. 2002. Osteological correlates of cervical musculature in Aves and Sauropoda (Dinosauria: Saurishia), with comments on the cervical ribs of Apatosaurus. - PaleoBios 22 (3): 1-6.

Yamada, H. 1973. Strength of Biological Materials. 297 pp., R. Krieger Publishing Company, New York, USA. 